\title{
O PRINCÍPIO DA EFICIÊNCIA NA ADMINISTRAÇÃO PÚBLICA
}

\author{
ROSIMEIRE VENTURA LEITE*
}

1. Introdução. 2. Princípios constitucionais. 3. Princípios constitucionais da Administração Pública. 4. Comentários sobre a Emenda Constitucional $n^{0}$ 19/98. 5. Princípio da eficiência. 6. Eficiência na Administração Pública e cidadania. 7. Conclusão. 8. Bibliografia.

\section{Introdução}

O presente estudo se propõe a analisar o princípio da eficiência no âmbito da Administração Pública brasileira, iniciando por algumas considerações sobre os princípios constitucionais para, em seguida, tecer breves comentários acerca dos princípios estabelecidos na Carta Magna como norteadores da atividade administrativa, inseridos no seu art. 37 , fazendo uma análise mais detida no princípio da eficiência, introduzindo explicitamente no texto constitucional com a Emenda $n^{\circ}$ $19 / 98$.

\section{Princípios constitucionais}

\subsection{Conceitos de princípios}

Segundo Silva (1996, v. 4, p. 447), a palavra princípio deriva do latim principium, indicando "o começo ou origem de qualquer coisa". No plural, princípios são "normas ou preceitos, que se fixaram para servir de norma a toda espécie de ação jurídica". Por fim, os princípios jurídicos "significam os pontos básicos, que servem de ponto de partida ou de elementos vitais do próprio Direito. Indicam o alicerce do Direito".

* Mestranda em Direito Constitucional pela UFC e Professora na Universidade Estadual da Paraíba - UEPB.

R. Dir. Adm., Rio de Janeiro, 226: 251-263, out./dez. 2001 
Destaca Espínola (1999, pp. 46-47) que o termo princípio é usado em diversos campos do conhecimento humano, sempre para designar " $[. .$.$] a estruturação de um$ sistema de idéias, pensamentos ou normas por uma idéia mestra, por um pensamento chave, por uma baliza normativa donde todas as demais idéias, pensamentos ou normas derivam, se reconduzem e/ou se subordinam".

Em se tratando, especificamente, da Ciência Jurídica, o termo princípio é utilizado:

[...] ora para designar a formulação dogmática de conceitos estruturados; por sobre o direito positivo, ora para designar determinado tipo de normas jurídicas e ora para estabelecer os postulados teóricos, as proposições juridicas construídas independentemente de uma ordem jurídica concreta ou de institutos de direito ou normas legais vigentes (ESPÍNDOLA, 1999, p. 49).

Nesse mesmo sentido Lucon (1999, p. 92) afirma que, "na Ciência Jurídica, os princípios servem de base axiológica e estruturante do conhecimento jurídico, sendo fonte de sua criação, aplicação ou interpretação".

Também Rocha $(1994$, p. 21) comenta que "no princípio repousa a essência de uma ordem, seus parâmetros fundamentais e direcionadores do sistema ordenado".

Uma das característias primordiais dos princípios atualmente é o reconhecimento de sua força vinculante, de sua normatividade. Consoante observa Bonavides (1998, p. 230-231), o conceito de princípios não pode prescindir do "traço da normatividade", idéia desenvolvida pela doutrina contemporânea. Neste contexto, tem-se como precursora, na identificação do caráter normativo dos princípios, a obra de Crisafulli (1952), para quem:

Princípio é, com efeito, toda norma jurídica, enquanto considerada como determinante de uma ou de muitas outras subordinadas, que a pressupõem, desenvolvendo e especificando ulteriormente o preceito em direções mais particulares (menos gerais), das quais determinam, e, portanto, resumem, potencialmente, o conteúdo: sejam, pois, estas efetivamente postas, sejam, ao contrário, apenas dedutíveis do respectivo princípio geral que as contém (apud BONAVIDES, 1998, p. 230).

Todavia, o reconhecimento da normatividade dos princípios, ou seja, a conversão dos princípios gerais em princípios constitucionais, não se deu de imediato, obedecendo, conforme enumera Bonavides (1998, p. 232-237), há três fases consecutivas: a jusnaturalista, em que os princípios pertenciam a uma esfera abstrata e metafísica, sendo sua normatividade questionável; a positivista, quando os princípios ingressam nos códigos, mas apenas como fonte de suprimento das lacunas da lei; $\mathrm{e}$, por fim, a fase pós-positivista, quando os princípios são inseridos nos textos constitucionais e erigidos à categoria de "[...] pedestal normativo sobre o qual se assenta todo o edifício jurídico dos novos sistemas constitucionais" (BONAVIDES, 1998, p.237). É a partir deste momento em que os princípios passam a ter sua normatividade reconhecida, colocando-se no topo do ordenamento jurídico, conquistando, assim, 
“[...] a dignidade de normas jurídicas vinculantes, vigentes e eficazes para muito além da atividade integratória do Direito" (ESPÍNDOLA, 1999, p. 59).

\subsection{Funções dos Princípios Constitucionais}

Os princípios desempenham um papel primordial dentro do ordenamento jurídico, o que é ressaltado por Canotilho (1992, p. 176), ao afirmar que "os princípios têm uma função normogenética e uma função sistêmica: são o fundamento de regras jurídicas e têm uma idoneidade irradiante que lhes permite 'ligar' ou cimentar objectivamente todo o sistema constitucional".

Também Bonavides (1988, pp. 254-255) observa que os princípios desempenham três funções primordiais: funcionam como fundamento do ordenamento jurídico, sendo este o aspecto mais relevante dos princípios; atuam também na tarefa de interpretação das normas, e, por fim, no trabalho de integração do Direito, preenchendo as lacunas das leis e dos costumes.

Verifica-se, portanto, a característica de serem os princípios base para o ordenamento jurídico, funcionando como fundamento da atividade do jurista e do intérprete da lei. Desse modo, as leis devem estar em harmonia com os princípios compreendidos, expressa ou implicitamente, na ordem constitucional, uma vez que estes representam valores a serem preservados, dotados de normatividade e de força cogente.

\section{Princípios constitucionais da Administração Pública}

O Estado - visando ao alcance dos fins para os quais foi criado, e que, em síntese, devem estar relacionados à busca do em comum - desempenha, no âmbito do poder que lhe foi atribuído, três principais grupos de atividades: a administrativa, a legislativa e a judiciária. São as funções estatais, conceituadas por Rocha como "formas específicas de exercício do poder político, previamente determinadas pelo direito, as quais, a juízo do legislador, constituem a estrutura mais adequada para alcançar os objetivos a que o Estado se propõe (1995, p. 12, grifo do autor).

Dentre estas funções, entretanto, interessa-nos mais diretamente a função administrativa, a fim de que possamos analisar os princípios que a Cara Magna estabelece como reguladores desta atividade estatal, notadamente o princípio da eficiência.

Segundo Silva (1996, v. 1, p. 89), o termo administração deriva do latim administrare, significando "governar, gerir, executar".

A Administração Pública, por sua vez, pode ser estendida sob aspectos diversos. Em sentido amplo e pelo critério subjetivo, explica Faria (1999, pp. 64-66) a Administração Pública abrange os três Poderes estatais - Executivo, Legislativo e Judiciário, com primazia para o Executivo. Sob um ponto de vista objetivo, entretanto, a Administração corresponde à função administrativa. Em sentido estrito, a Administração Pública compreende o "[...] conjunto de órgãos e entidades que a integram", se observada sob o aspecto subjetivo. Por fim, objetivamente, e ainda em sentido estrito, a Administração Pública engloba “[...] a prestação de serviços 
públicos, o exercício da polícia administrativa e a atividade de fomento" (FARIA, 1999, p. 66).

Desse modo, à Administração Pública cabe, dentre outras atividades, prestar o serviço público, entendido este, em sentido estrito, como "toda atividade material que a lei atribui ao Estado para que a exerça diretamente ou por meio de seus delegados, com o objetivo de satisfazer concretamente às necessidades coletivas, sob regime jurídico total ou parcialmente público" (DI PIETRO, 2001, p. 98) ${ }^{1}$

Assim, através da atividade administrativa - conferida preferencialmente ao Poder Executivo, dentro do sistema de separação de poderes - o Estado realiza determinadas ações para atender as necessidades coletivas, devendo, por conseguinte, pautar-se pelo que a lei estabelece e pelos interesses da sociedade na consecução de seus fins.

No exercício desta atividade, portanto, faz-se necessária a observância de leis e de princípios, a limitar a ação do administrador, a fim de que se preserve o interesse social.

É neste contexto que são estabelecidos - no art. $37 / 88^{2}$ da Constituição Federal de 1988 - os princípios constitucionais que regem a Administração Pública, embora outros possam ser encontrados no texto constitucional de forma implícita ou explícita. Assim, a atividade administrativa deve se regular pelos princípios da legalidade, impessoalidade, moralidade, publicidade e, a partir da Emenda Constitucional n. 19, de 4.6.1998, também pelo princípio da eficiência.

Cuidou o legislador constitucional, portanto, de estabelecer explicitamente alguns princípios de observância obrigatória no desenvolvimento da atividade administrativa, de modo a preservar o interesse público, garantindo o cidadão contra abusos e arbitrariedades intoleráveis em um Estado de Direito. Nesse sentido, afirma Di Pietro (2001, p. 67) que:

Sendo o Direito Administrativo de elaboração pretoriana e não codificado, os princípios representam papel relevante nesse ramo do direito, permitindo à Administração e ao Judiciário estabelecer o necessário equilíbrio entre os direitos dos administrados e as prerrogativas da Administração.

Analisemos, pois, cada um destes princípios, e, de forma mais detida, o princípio da eficiência, objeto de estudo deste trabalho.

Com efeito, no âmbito da Administração Pública, o princípio da legalidade ganha especial importância, restringindo a atuação do administrador ao que está previsto expressamente na lei, o que representa uma das maiores garantias dos administrados contra os excessos dos governantes.

1 Na definição de Meirelles (1999, p. 297), “serviço público é todo aquele prestado pela Administração ou por seus delegados, sob normas e controles estatais, para satisfazer necessidades essenciais ou secundárias da coletividade ou simples conveniências do Estado". E acrescenta: "fora dessa generalidade não se pode, em doutrina, indicar as atividades que constituem serviço público, porque variam segundo as exigências de cada época". 
Para Filho (2000, p. 25-26), "a legalidade é a base e a matriz de todos os demais princípios constitucionais que instruem, condicionam, limitam e vinculam as atividades administrativas. Os demais princípios constitucionais servem para esclarecer e explicitar o conteúdo do princípio maior ou primário da legalidade".

O princípio da legalidade surge com o chamado Estado de Direito, definido por Canotilho (1999, p. 52) como aquele "em que todos os seus esquemas organizatórios, em todos os seus procedimentos, incorpore os princípios jurídicos que, de forma indisponível por qualquer poder, dão validade ou legitimidade a uma ordem jurídica". É ainda o mesmo autor que destaca: "a lei ocupa ainda um lugar privilegiado na estrutura do Estado de Direito porque ela permanece como expressão da vontade comunitária veiculada através de órgãos representativos dotados de legitimação democrática directa" (1999, p. 64). Também Faria $(1999$, p. 64) define o Estado de Direito como "aquele que se submete às leis por ele próprio criadas, voltadas para a promoção do interesse social".

Ainda com referência à legalidade, afirma Di Pietro (2001, p. 68) que "segundo o princípio da legalidade, a Administração Pública só pode fazer o que a lei permite", o que difere das relações entre os particulares, nas quais aplica-se o princípio "da autonomia da vontade, que lhes permite fazer tudo o que a lei não proíbe".

Desse modo, a legalidade é regra primeira a ser observada no desempenho da atividade administrativa, vinculando os atos do administrador, em prol do interesse público.

Contudo, além da legalidade, é necessária também a observância do princípio da impessoalidade, que Meirelles (1999, p. 85) utiliza como sinônimo do princípio da finalidade, o qual "impõe ao administrador público que só pratique o ato para o seu fim legal", fim este que só pode se identificar com o interesse público. E acrescenta este mesmo autor, mais adiante, que "o que o princípio da finalidade veda é a prática de ato administrativo sem interesse público ou conveniência para a Administração, visando unicamente a satisfazer interesses privados, por favoritismo ou perseguição dos agentes governamentais, sob a forma de desvio de finalidade" $(1999$, p. 86).

É pelo princípio da impessoalidade também que se visa a evitar promoções pessoais por parte dos agentes públicos, nos termos do art. $37, \S 1^{\circ}$. CF $/ 88^{2}$, cuja violação pode configurar improbidade administrativa, conforme a Lei n. 8.429/92.

Já pelo princípio da moralidade, insere-se o elemento ético na atividade administrativa. De fato, a moralidade refere-se aos valores morais e éticos que devem estar imanentes na conduta do administrador público. Assim, não basta apenas seguir estritamente o que a lei determina, mas também guiar-se pela moralidade, conforme os valores prevalentes em uma sociedade em determinada época.

$2 \mathrm{CF} / 88$, art. $37, \S 1^{\circ}$. "A administração pública direta e indiretamente de qualquer dos Poderes da União, dos Estados, do Distrito Federal e dos Municípios obedecerá aos princípios de legalidade, impessoalidade, moralidade, publicidade e eficiência e, também, ao seguinte: [...] "A publicidade dos atos, programas, obras, serviços e campanhas dos órgãos públicos deverá ter caráter educativo, informativo ou de orientação social, dela não podendo constar nomes, símbolos ou imagens que caracterizem promoção pessoal de autoridades ou servidores públicos". 
Segue-se ainda o princípio da publicidade, sendo, pois, dever da Administração dar publicidade aos atos que irão produzir efeitos perante terceiros, sendo também uma forma de viabilizar o controle por parte da sociedade, de modo que o cidadão possa utilizar os mecanismos constitucionais e legais para tal fim. Trata-se, portanto, de requisito de eficácia do ato administrativo para que produza seus efeitos externamente.

Neste contexto, destaca Oliveira Moraes (1999, p. 107) a importância da veracidade da informação prestada pelos agentes administrativos:

O princípio constitucional da publicidade gera para o cidadão o direito à informação - a transparência dos atos, procedimentos e contratos administrativos, e mais do que isso, à informação verdadeira, e para a Administração Pública o dever de motivar expressamente os atos administrativos.

E acrescenta ainda que:

[...] exige-se nas relações humanas que os comportamentos sejam, além de frontais e não ocultos, sinceros, e não mentircsos; sejam autênticos e verazes, e não simulados ou dissimulados. Assim também nas relações com a Administração Pública não se concebem os procedimentos ocultos, mentirosos e inautênticos (OLIVEIRA MORAES, 1999, p. 108).

Por fím, além destes princípios já mencionados, foi inserido, pela Emenda Constitucional n. 19/98, no citado dispositivo constitucional, o princípio da eficiência, do qual nos ocuparemos mais adiante.

Entretanto, além dos princípios explícitos no caput do art. $37, \mathrm{CF} / 88$, outros existem, elencados pela doutrina, e que igualmente se aplicam à atividade administrativa. São os princípios da supremacia do interesse público, da presunção de legitimidade ou de veracidade, da especialidade, do controle ou tutela, da autotuela, da hierarquia, da continuidade do serviço público, da razoabilidade, da proporcionalidade, da motivação e da segurança jurídica. ${ }^{3}$

\section{Comentários sobre a Emenda Constitucional no $19 / 98$ (EC 19/98)}

Pela exposição de motivos da proposta de emenda constitucional referente às disposições que regem a Administração Pública, o regime jurídico e a disciplina da estabilidade dos servidores públicos, justificou-se a chamada reforma administrativa como uma medida imprescindível para superar a crise do Estado (PEREIRA JÚNIOR, 1999, p. 1).

A Emenda Constitucional n. 19, de 4.6.98, portanto, inseriu-se em um conjunto de medidas que visavam a superar a referida crise, a qual se manifestava em vários setores e também na prestação do serviço público.

3 Citados por Bastos (1999, pp. 28-49) e por Di Pietro (2001, pp. 67-84), dentre outros autores. 
Foi neste contexto que a citada emenda introduziu a reforma administrativa, objetivando adaptar a atividade administrativa do Estado às novas exigências da sociedade moderna, sobretudo no que diz respeito ao aumento da eficiência e da qualidade no serviço público, promovendo-se a contenção dos gastos públicos e buscando-se evitar os desperdícios arraigados na cultura da Administração Pública brasileira.

Todavia, para além das justificativas apresentadas, não se pode estudar a referida emenda sem contextualizá-la nas exigências da política neoliberal, aspecto que é destacado por Oliveira Moraes (1999, pp. 126-128), nos seguintes termos:

A reforma administrativa objeto da EC 19, de 4.6.98, é resultado da necessidade de adaptar as disposições dos artigos 37 e 39 da Constituição Federal de 1988 com o vitorioso credo neoliberal exigente do modelo de 'Estado mínimo' e apoiado no discurso de legitimidade pela eficiência (grifo da autora).

Acrescentando, em seguida, que a mencionada emenda em como causas "a necessidade de adaptar o texto constitucional de 1988 à política de desestatização do atual Governo", em como "reduzir os gastos públicos" (1999, p. 127).

É certo, portanto, que o setor público sempre foi alvo de críticas e de insatisfações por parte da sociedade, sendo constantemente qualificado como ineficiente, burocrático e lento. Contudo, necessário atentar para os interesses que motivaram a introdução a citada emenda, que teve como um dos seus pilares a eficiência e em cujas raízes estão as idéias do neoliberalismo. Neoliberalismo que Paulo Bonavides (1999, p. 55-57) aponta como uma das causas da crise dos países em desenvolvimento.

Por fim, acrescente-se que a EC 19/98, modificando o art. $41, \mathrm{CF} / 88^{4}$, inseriu a possibilidade de o servidor público perder o cargo mediante procedimento de avaliação periódica de desempenho, nos termos de lei complementar, além da exigência de uma avaliação especial de desempenho por comissão especialmente constituída para efeitos de aquisição da estabilidade por parte do servidor público.

\section{Princípio da Eficiência}

É neste âmbito da reforma administrativa que se insere o princípio da eficiência, introduzido no art. 37, CF/88, pela Emenda Constitucional n. 19/98, de modo que o referido dispositivo constitucional passa a ter a seguinte redação:

$4 \mathrm{CF} / 88$, art. $41, \S 1^{\circ}$. O servidor público estável só perderá o cargo: [...] III — mediante procedimento de avaliação periódica de desempenho, na forma de lei complementar, assegurada ampla defesa. [...] $\S 4^{\circ}$ Como condição para a aquisição da estabilidade, é obrigatória a avaliação especial de desempenho por comissão instituída para essa finalidade. 
Art. 37. A administração pública direta e indireta de qualquer dos Poderes da União, dos Estados, do Distrito Federal e dos Municípios obedecerá aos princípios de legalidade, impessoalidade, moralidade, publicidade e eficiência $[. .$.$] (grifo nosso).$

Todavia, embora a referida emenda tenha incluído de forma expressa o princípio da eficiência aos outros princípios que regem a Administração Pública, a eficiência já existia implicitamente, conforme se verá no tópico seguinte.

\subsection{Antecedentes históricos}

Antes de ser inserido expressamente no art. $37 \mathrm{da} C F / 88$, o princípio da eficiência já era mencionado na jurisprudência, estando também implícito no ordenamento constitucional.

Com efeito, o art. 74, II, CF/88 referia-se, antes mesmo da emenda citada, à eficiência da gestão orçamentária, financeira e patrimoniai na Administração federal, nos seguintes termos:

Art. 74. Os Poderes Legislativo, Executivo e Judiciário manterão, de forma integrada, sistema de controle interno com a finalidade de:

[...]

II - comprovar a legalidade e avaliar os resultados, quanto à eficácia e eficiência, da gestão orçamentária, financeira e patrimonial nos órgãos $e$ entidades da administração federal, bem como da aplicação de recursos públicos por entidades de direito privado [grifo nosso].

Também o Dec.-lei n.200, de 25 de fevereiro de 1967 (Reformar Administrativa Federal) prevê o controle de resultados no que se refere às atividades do Executivo (arts. 13 e 25, V), contendo ainda outras referências ao citado princípio nos arts. 23, VIII, 26, III e 100 (FARIA, 1999, p. 73-74).

No que se refere à jurisprudência, menciona Esteves $(2000$, p. 10) a seguinte decisão do Superior Tribunal de Justiça:

Administrativo - Funcionário - Estágio probatório - Dispensa - Sindicância - Legalidade.

I - Servidora pública em estágio probatório pode ser dispensada por não convir à Administração a sua permanência, após ter sido apurado em sindicância regular, com a ampla defesa assegurada, que praticou atos incompatíveis com a função do cargo em que se encontrava investida. $O$ estágio probatório tem por escopo verificar se a pessoa habilitada no concurso preenche os requisitos legais exigidos, sua idoneidade moral, a disciplina, a eficiência, a aptidão, a assiduidade.

II - Recurso improvido. A Administração Pública é regida por vários princípios: legalidade, impessoalidade, moralidade e publicidade (Const. Art. 37). Outros evidenciam-se na Carta Política. Dentre eles, o princípio 
da eficiência. A atividade administrativa deve orientar-se para alcançar resultado de interesse público.

Vê-se, assim, que o princípio da eficiência já estava implícito no ordenamento jurídico brasileiro, tendo apenas a Emenda Constitucional n. 19 acrescentando-o de forma explícita ao rol do art. 37 da Constituição Federal de 1988. Comentando sobre o tema, Pereira Júnior (1999, p. 41-42), argumenta:

No que tange ao arrolamento da eficiência entre os princípios reitores da atividade administrativa estatal, só se pode compreender como uma figura de estilo, um reforço de linguagem para enfatizar o que é inerente à Administração Pública e é dela reclamado pelos administrados, justificadamente. A sociedade não organiza e mantém o Estado para ser ineficiente, embora ineficiências podem ser, e são, encontráveis; em setores de qualquer empreendimento privado.

Para Bastos (1999, p. 50) o princípio da eficiência, com a Emenda Constitucional n. 19/98, passa a ter um novo perfil, de modo que:

[...] a grande preocupação concentra-se no desempenho da Administração Pública, ou seja, buscam-se melhores resultados em suas atividades, com a substituição dos obsoletos mecanismos de fiscalização dos processos pelo controle dos resultados, sempre tendo em vista a realização do interesse público.

\subsection{Conceito}

A questão da eficiência parte da idéia de que há uma relação jurídica entre o Estado e os indivíduos, gerando direitos e obrigações recíprocas, de modo que à Administração cabe o cumprimento de seus deveres da forma mais eficiente possível, a fim de atender aos interesses da sociedade e, em última análise, aos fins que justificam a existência do Estado, enquanto modalidade específica de organização social.

Seguindo o entendimento de Alexandre de Moraes (1999, p. 294), o princípio da eficiência pode ser compreendido como:

[...] aquele que impõe à Administração pública direta e indireta e a seus agentes a persecução do bem comum, por meio do exercício de suas competências de forma imparcial, neutra, transparente, participativa, eficaz, sem burocracia e sempre em busca da qualidade, primando pela adoção dos critérios legais e morais necessários para a melhor utilização possível dos recursos públicos, de maneira a evitar-se desperdício e garantir-se uma maior rentabilidade social.

Para Meirelles (1999, p. 89 e 91), "o princípio da eficiência exige que a atividade administrativa seja exercida com presteza, perfeição e rendimento funcional". Tal 
princípio, por sua vez, faz surgir para o administrador o "dever de eficiência", que o citado autor afirma corresponder ao "dever de boa administração", previsto pelos italianos.

\subsection{Princípio da eficiência no Direito estrangeiro}

O princípio da eficiência também está presente no ordenamento jurídico de outros países, expressa ou implicitamente, conforme estudo de direito comparado realizado por Alexandre de Moraes ao comentar o citado princípio (1999, pp. 292293).

Assim, a Constituição Espanhola, de 27.12.1978, dispõe expressamente sobre a eficiência no art. 103, nos seguintes termos:

La Administración Pública sirve con objetividad los intereses generales y actúa de acuerdo ocn los principios de "eficacia", jerarquía, descentralización, desconcentración y coordinación, con sometimiento pleno a la ley y al Derecho (grifo nosso).

Do mesmo modo, a Constituição da República das Filipinas, de 15/10/1986, no art. IX, B, seção 3, e no art. XI, Seção I, no qual estabelece que "o serviço público é um compromisso com a causa pública. Os servidores públicos deverão estar sempre prontos a prestar contas ao povo, servi-lo da forma mais responsável, íntegra, leal e eficiente possível" (MORAES, 1999, p. 292).

Já a Constituição Portuguesa não prevê expressamente o princípio da eficiência. De fato, acerca dos princípios fundamentais da Administração Pública, estabelece no art. 266 , n. 2 , que "os órgãos e agentes administrativos estão subordinados à Constituição e à lei e devem actuar, no exercício das duas funções, com respeito pelos princípios da igualdade, da proporcionalidade, da justiça, da imparcialidade e da boa fé". Contudo, no art. 267, o dever de eficiência está implícito, ao se determinar que:

A Administração Pública será estruturada de modo a evitar a burocratização, a aproximar os serviços das populações e assegurar a participação dos interessados na sua gestão efectiva, designadamente por intermédio de associações públicas, organizações de moradores e outras formas de representação democrática.

\subsection{Conteúdo do princípio da eficiência}

A eficiência abrange o desempenho de um serviço público em que o interesse coletivo prevaleça sobre a burocracia, visando-se sempre à busca da celeridade, da economia de material e da obtenção dos melhores resultados.

Conforme ensina Meirelles (1999, pp. 91-92), o princípio da eficiência compreende a "produtividade", a "perfeição do trabalho", bem como a "adequação técnica aos fins visados pela Administração", abrangendo, pois, uma aferição dos 
"aspectos quantitativo e qualitativo do serviço", a fim de que a Administração tenha um bom desempenho.

Di Pietro (2001, p. 83), por sua vez, destaca que o princípio da eficiência pode ser visto sob dois aspectos: "em relação ao modo de atuação do agente público, do qual se espera o melhor desempenho possível de suas atribuições, para lograr os melhores resultados; e em relação ao modo de organizar, estruturar, disciplinar a Administração Pública".

Já Alexandre de Moraes (1999, pp. 295-298), elenca as seguintes características da eficiência na administração pública: direcionamento da atividade e dos serviços públicos à efetividade do bem comum; imparcialidade; neutralidade; transparência; participação e aproximação dos serviços públicos da população; eficácia; desburocratização; e busca da qualidade.

Para Oliveira Moraes (1999, p. 128), entretanto, "eficiência é termo fluido e impreciso que traduz o senso comum de obtenção de resultados positivos nos desempenhos das atividades administrativas", lembrando, mais adiante, que o conteúdo deste pricípio deve atender inexoravelmente "às exigências da cidadania".

\section{Eficiência na Administração Pública e cidadania}

Já no art. $1^{\circ}$, II, estabelece a $\mathrm{CF} / 88^{5}$ ser a cidadania um dos fundamentos do Estado brasileiro. Desse modo, em todos os seus segmentos deve o Estado moldar suas atividades no sentido da realizá-la, como uma necessidade básica da própria concretização da democracia.

A administração pública, por excelência, deve visar à realização do bem comum e à satisfação dos interesses sociais, conjugando todos os recursos do Estado para a consecução deste fim, otimizando todo o potencial de seus agentes para uma prestação cada vez melhor dos seus serviços.

Todavia, a Administração Pública tornou-se refúgio de práticas inescrupulosas, completamente distanciadas do interesse coletivo e o serviço público passou a se identificar com a ineficiência, a burocracia e a lentidão. Tudo isso, em parte, pela inobservância dos ditames constitucionais, pelo descaso em relação às necessidades sociais e pela própria falta de fiscalização, quer seja dos órgãos competentes, quer seja da sociedade.

Este quadro trouxe profundos prejuízos para a população, vítima permanente de um serviço público insatisfatório e, não raro, violador da dignidade da pessoa humana.

Agora insere-se o princípio da eficiência no âmbito da Administração Pública, atendendo-se a ditames da política neoliberal, como destaca Oliveira Moraes (1999, p. 126-128).

5 CF/88, Art. $1^{\circ}$. A República Federativa do Brasil, formada pela união indissolúvel dos Estados e Municípios e do Distrito Federal, constitui-se em Estado Democrático de Direito e tem como fundamentos: [...]. II - a cidadania. 
Todavia, a eficiência deve ser um princípio inerente à Administração, independentemente de sua previsão expressa, pois representa requisito essencial para a efetivação da cidadania, na medida em que significa um serviço público voltado para a satisfação do interesse público e não para interesses pessoais.

Por outro lado, não é a previsão explícita do princípio da eficiência que vai garantir um serviço público de melhor qualidade e a superação das mazelas que a Administração ainda apresenta em nosso país. É necessário mais do que a previsão constitucional. É imprescindível uma mudança de valores sociais e culturais, a fim de que os recursos da Administração possam ser utilizados de maneira equilibrada, sem desperdícios, sem favoritismos, como coisas públicas que são.

A eficiência na Administração Pública, portanto, deve guiar-se pela finalidade de concretização da cidadania, cabendo à sociedade também buscar a realização dos seus direitos, fiscalizando as atividades estatais, a conduta de seus representantes, pois só assim age como verdadeiro cidadão.

Necessário, deste modo, que se faça valer o art. $37, \S 3^{\circ}, \mathrm{CF} / 88$, que traz norma essencial para a efetivação de uma prestação do serviço público eficiente, ao prevê que:

A lei disciplinará as formas de participação do usuário na administração pública direta e indireta, regulando especialmente:

I - as reclamações relativas à prestação dos serviços públicos em geral, asseguradas a manutenção de serviços de atendimento ao usuário e a avaliação periódica, externa e interna, da qualidade do serviço.

Entretanto, se as pessoas continuarem aceitando como normais determinadas práticas que contrariam as regras mais básicas de moralidade na Administração Pública, não será a inserção de um princípio que irá resolver o problema.

\section{Conclusão}

Após este estudo sobre o princípio da eficiência na Administração Pública brasileira, pode-se chegar às seguintes conclusões:

- A eficiência não é um princípio novo no ordenamento jurídico brasileiro, de modo que a EC/19 apenas o inseriu de forma expressa, aumentando o rol de princípios constitucionais da Administração Pública, contida no art. 37, CF/88;

- Esse princípio se insere no contexto da reforma do Estado, também chamada de reforma administrativa, tendo por finalidade a busca da qualidade no serviço público, evitando-se os desperdícios;

- Por outro lado, visa o princípio da eficiência, e a EC 19/98 na qual está incluído, a atender a interesses das idéias neoliberais, moldando o Estado às exigências desta política;

- Contudo, a eficiência na Administração Pública deve ter em vista, primordialmente, a efetivação da cidadania e o atendimento do interesse público, através da prestação de um serviço público cada vez mais qualificado e voltado para as necessidades sociais; 
- Verifica-se, por fim, que o fato de tornar este princípio expresso na Constituição Federal não vai, por si só, garantir a melhoria no serviço público, pois a reforma do Estado e o melhor funcionamento da Administração Pública passam, sobretudo, por profundas mudanças culturais, que visem efetivamente a direcionar o serviço público para o cidadão.

\section{Bibliografia}

BASTOS, Celso Ribeiro. Curso de direito administrativo. São Paulo: Saraiva, 1999. BONAVIDES, Paulo. Curso de direito constitucional. 7. ed. São Paulo: Malheiros, 1998.

. Do país constitucional aos país neocolonial. São Paulo: Malheiros, 1999.

CANOTILHO, J.J. Gomes. Estado de Direito. Lisboa: Gradiva, 1999.

Direito Constitucional. 5. ed. Coimbra: Almedina, 1992.

DI PIETRO, Maria Sylvia Zanella. Direito administrativo. 13. ed. São Paulo: Atlas, 2001.

ESPÍNDOLA, Ruy Samuel. Conceito de Princípios Constitucionais. 1. ed. São Paulo: Revista dos Tribunais, 1999.

ESTEVES, Juliana Teixeira. O princípio constitucional da eficiência e sua aplicação à Administração Pública. Jornal do Direito, Recife, jan./fev. 2000, p. 10.

FARIA, Edimur Ferreira. Curso de direito administrativo positivo. 2. ed. Belo Horizonte: Del Rey, 1999.

FILHO, Marino Pazzaglini. Principios constitucionais reguladores da Administração Pública. São Paulo: Atlas, 2000.

LUCON, Paulo Henrique dos Santos. Garantia do Tratamento Paritário da Partes. In: TUCCI, José Rogério Cruz e (coord.). Garantias Constitucionais do Processo Civil. São Paulo: Revista dos Tribunais, 1999, pp. 91-127.

MEIRELLES, Hely Lopes. Direito administrativo brasileiro. 24. ed. São Paulo: Malheiros, 1999.

MORAES, Alexandre de. Direito constitucional. 5. ed. São Paulo: Atlas, 1999.

OLIVEIRA MORAES, Germana de. Controle jurisdicional da Administração Pública. São Paulo: Dialética, 1999.

PEREIRA JÚNIOR, Jessé Torres. Da reforma administrativa constitucional. Rio de Janeiro: Renovar, 1999.

ROCHA, Carmem Lúcia Antunes. Princípios constitucionais da Administração Púbica. Belo Horizonte: Del Rey, 1994.

ROCHA, José de Albuquerque. Estudos sobre o Poder Judiciário. São Paulo: Malheiros, 1995.

SILVA, De Plácido e. Vocabulário Jurídico. 12 ed. Rio de Janeiro: Forense, 1996, v. 1 e 2 . 


\section{Da Reforma Administrativa Constitucional}

Jessé Torres Pereira Júnior

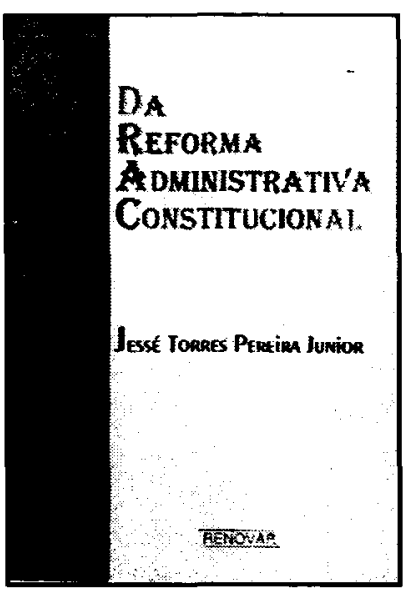

Esta obra oferece ao estudioso elementos que lhe descortinarão as perspectivas de apoio $\mathrm{e}$ as de objeção às modificaçōes trazidas pela Emenda Constitucional $n^{\circ}$ 19/98. É de inestimável e valiosa contribuiçào crítica e documental que permite ao leitor navegar com segurança nos meandros da Reforma Administrativa Constitucional. Como estudo pioneiro, lastreado de ampla informação comparativa e avaliação crítica, abre caminho seguro ao entendimento da substância da Reforma Administrativa e firma balizas adequadas para sua execução.

Ref. 0212

Form. 16x23

503 págs.

\section{Das Nulidades dos Atos Jurídicos}

Martinho Garcez

Esta obra trata do estudo e diagnóstico das moléstias dos atos jurídicos, as "Nulidades dos Atos Jurídicos" abrangem toda a esfera do código civil. Foi necessário percorrer todo o ciclo do direito civil para examinar as moléstias dos atos jurídicos e diagnosticá-las, apontando-as, depois de ter estudado a sua origem ou as suas causas, criando um processo novo de anatomia jurídica.

Ref. 0149

Form. 16x23

Encadernado 410 págs. 1997

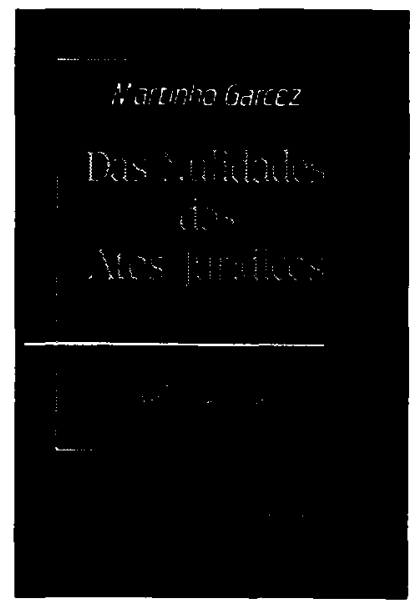

